Utah State University

DigitalCommons@USU

1999

\title{
Measurement of Technical Efficiency in Public Education: A Stochastic and Nonstochastic Production Function Approach
}

\author{
Kalyan Chakraborty \\ Utah State University \\ Basudeb Biswas \\ Utah State University \\ W. Cris Lewis \\ Utah State University
}

Follow this and additional works at: https://digitalcommons.usu.edu/eri

\section{Recommended Citation}

Chakraborty, Kalyan; Biswas, Basudeb; and Lewis, W. Cris, "Measurement of Technical Efficiency in Public Education: A Stochastic and Nonstochastic Production Function Approach" (1999). Economic Research Institute Study Papers. Paper 162.

https://digitalcommons.usu.edu/eri/162

This Article is brought to you for free and open access by the Economics and Finance at DigitalCommons@USU. It has been accepted for inclusion in Economic Research Institute Study Papers by an authorized administrator of DigitalCommons@USU. For more information, please contact digitalcommons@usu.edu.

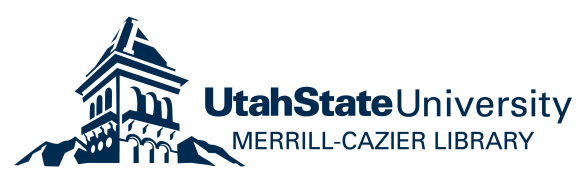


Economic Research Institute Study Paper

ERI \#99-12

\author{
MEASUREMENT OF TECHNICAL EFFICIENCY IN PUBLIC \\ EDUCATION: A STOCHASTIC AND NONSTOCHASTIC \\ PRODUCTION FUNCTION APPROACH
}

\author{
by \\ KALYAN CHAKRABORTY \\ Department of Agricultural and Applied Economics \\ Texas Tech University \\ Lubbock, TX 79409-2132 \\ BASUDEB BISWAS \\ W. CRIS LEWIS \\ Department of Economics \\ Utah State University \\ 3530 Old Main Hill \\ Logan, UT 84322-3530
}

February 1999 
MEASUREMENT OF TECHNICAL EFFICIENCY IN PUBLIC EDUCATION:

A STOCHASTIC AND NONSTOCHASTIC PRODUCTION FUNCTION APPROACH

\author{
Kalyan Chakraborty, Post-Doctoral Research Associate \\ Department of Agricultural and Applied Economics \\ Texas Tech University \\ Lubbock, TX 79409-2132 \\ Basudeb Biswas, Professor \\ W. Cris Lewis, Professor \\ Department of Economics \\ Utah State University \\ 3530 Old Main Hill \\ Logan, UT 84322-3530
}

The analyses and views reported in this paper are those of the author(s). They are not necessarily endorsed by the Department of Economics or by Utah State University.

Utah State University is committed to the policy that all persons shall have equal access to its programs and employment without regard to race, color, creed, religion, national origin, sex, age, marital status, disability, public assistance status, veteran status, or sexual orientation.

Information on other titles in this series may be obtained from: Department of Economics, Utah State University, 3530 Old Main Hill, Logan, Utah 84322-3530.

Copyright (C) 1999 by Kalyan Chakraborty, Basudeb Biswas, and W. Cris Lewis. All rights reserved. Readers may make verbatim copies of this document for noncommercial purposes by any means, provided that this copyright notice appears on all such copies. 


\title{
MEASUREMENT OF TECHNICAL EFFICIENCY IN PUBLIC EDUCATION: A STOCHASTIC AND NONSTOCHASTIC PRODUCTION FUNCTION APPROACH Kalyan Chakraborty, Basudeb Biswas, and W. Cris Lewis
}

\begin{abstract}
This paper uses both the stochastic and nonstochastic production function approach to measure technical efficiency in public education in Utah. The stochastic specification estimates technical efficiency, assuming half normal and exponential distributions. The nonstochastic specification uses two-stage DEA to separate the effects of fixed inputs on the measure of technical efficiency. The empirical analysis shows substantial variation in efficiency among school districts. While these measures are insensitive to the specific distributional assumptions about the one-sided component of the error term in stochastic specification, they are sensitive to the treatment of fixed socioeconomic inputs in the two-stage DEA.

JEL Code: D20, R30, C14
\end{abstract}




\section{MEASUREMENT OF TECHNICAL EFFICIENCY IN PUBLIC EDUCATION: \\ A STOCHASTIC AND NONSTOCHASTIC PRODUCTION FUNCTION APPROACH ${ }^{1}$}

\section{Introduction}

Efficiency in the public education system is a significant issue in the United States. Nationwide, real expenditure per student in public education increased over $8 \%$ per year between 1960 and 1993, but output, as generally measured by standardized test scores, has not increased and, in some cases (e.g., the verbal SAT score), has declined. ${ }^{2}$ One explanation is that resources are not being utilized efficiently. There may be productive or technical inefficiency and/or allocative or price inefficiency (i.e., given the relative prices of inputs, the cost-minimizing input combination is not used). This paper evaluates the technical inefficiency in public schools using data from Utah school districts.

The pioneering work by Farrell (1957) provides the definition and conceptual framework for both technical and allocative efficiency. While technical efficiency refers to failure to operate on the production frontier, allocative efficiency generally refers to the failure to meet the marginal conditions for profit maximization. Since Farrell's original work, considerable effort has been directed at refining the measurement of technical efficiency. The literature is broadly divided into deterministic and stochastic frontier methodologies. ${ }^{3}$ The deterministic nonparametric approach that

\footnotetext{
${ }^{1}$ Post-Doctoral Research Associate, Department of Agricultural and Applied Economics, Texas Tech University, Lubbock TX 79409-2132; and Professor and Professor, Department of Economics, Utah State University, Logan, UT 84322-3530.

${ }^{2}$ See U. S. Department of Commerce (1994), Tables 239, 264, and 265.

${ }^{3}$ See Ali and Byerlee (1991), Lovell (1993), Greene (1993), and Coelli (1995) for a detailed discussion on the methods for analyzing technical efficiency.
} 
developed out of mathematical programming is commonly known as data envelopment analysis (DEA), and the parametric approach that estimates technical efficiency within a stochastic production, cost, or profit function model, is called the stochastic frontier method. Both approaches have advantages and disadvantages, which are elaborately discussed in Forsund, Lovell, and Schmidt (1980). DEA has been used extensively in measuring efficiency in the public sector (e.g., education), where market prices for output are not available. For example, Levin (1974), Bessent and Bessent (1980), Bessent et al. (1982), and Grosskopf and Weber (1989) use this method to estimate efficiency in public education. The stochastic frontier methodology was used by Barrow (1991) to estimate a stochastic cost frontier using data from schools in England. Wyckoff and Lavinge (1991) and Cooper and Cohn (1997) estimate technical efficiency using school district data from New York and South Carolina, respectively. Grosskopf et al. (1991) use the parametric approach to estimate allocative and technical efficiency in Texas school districts. The recent literature has seen a convergence of the two approaches and their complementarity is being recognized. ${ }^{4}$

However, there is a lack of empirical evidence in the literature about the proximity of these two approaches in measuring technical efficiency. Policy formulations based on the efficiency estimates using either method may not be accurate because of the inherent limitations of each. Prior to policy action being taken, the stability of the technical efficiency estimates based on the parametric method should be evaluated by comparing them against those determined by the nonparametric method.

${ }^{4}$ The Journal of Econometrics (1990) devotes an entire supplemental issue to parametric and nonparametric approaches to frontier analysis. 
In this study, technical efficiency estimates for each school district, using the stochastic frontier method and the Tobit residuals from the two-stage DEA model, are compared. In the two-stage DEA model, technical efficiency scores obtained from DEA using controllable inputs are regressed on the socioeconomic status of the students (SES) and other environmental factors. Residuals in such regression models measure pure technical efficiency after accounting for fixed SES and environmental factors.

The empirical analysis uses data from the 40 school districts in Utah for the academic year 1992-93. A standardized test score for the 11th grade students is used as a measure of school output, and two classes of inputs are included. The first, considered to be subject to control by school administrators, includes the student/teacher ratio, percentage of teachers having an advanced degree, and percentage of teachers with more than 15 years of experience. The second class includes such uncontrollable factors as the socioeconomic status of the students, education level of the local population, and net assessed real property value per student. The objective of the study is to measure technical efficiency at the individual school district level using both stochastic and nonstochastic estimation methods and to identify the sources of inefficiency.

This paper is organized as follows. First, the relevant literature is reviewed, and this is followed by a definition of educational production function. Next, the stochastic and DEA specifications of technical inefficiency are discussed. Finally, the data set is discussed, and the empirical results are presented.

\section{Background}

For a given technology and set of input prices, the production frontier defines the maximum 
output forthcoming from a given combination of inputs. Similarly, the cost frontier defines the minimum level of cost for providing a certain level of output given input prices. Finally, the profit frontier defines the maximum profit attainable given input and output prices. Inefficiency is measured by the extent that a firm lies below its production and profit frontier and above its cost frontier. Koopmans (1951) defines a technically efficient producer as one who cannot increase the production of any one output rate without decreasing another or without increasing some input. Debreu (1951) and Farrell (1957) offer a measure of technical efficiency as one minus the maximum equiproportionate reduction in all inputs that still allows continuous production of a given output rate (Lovell 1993).

The earliest study that measures technical inefficiency in education production is Levin (1974; 1976). He used the Aigner and Chu (1968) parametric nonstochastic linear programming model to estimate the coefficients of the production frontier, and found that parameter estimation by ordinary least square (OLS) does not provide correct estimates of the relationship between inputs and output for technically efficient schools — it only determines an average relationship. Klitgaard and Hall (1975) use OLS techniques to find that schools with smaller classes and better paid and more experienced teachers produce higher achievement scores. However, their study also is based on an average relationship rather than an individual school-specific relationship between inputs and output.

Among the studies on technical efficiency in public schools using the DEA method, the earliest was done by Charnes, Cooper, and Rhodes (1978), who evaluated the efficiency of individual schools relative to a production frontier. Bessent and Bessent (1980) and Bessent et al. (1982) made further refinements by incorporating a nonparametric form of the production function, 
introducing multiple outputs, and identifying sources of inefficiency for an individual school. Further extensions were made by Ray (1991) and McCarty and Yaisawarng (1993), who considered controllable inputs in the first stage of the DEA model to measure technical efficiency. Then the SES and environmental (i.e., noncontrollable) inputs were used as regressors in the second stage using OLS or a Tobit model, and the residual was analyzed to determine the performance of each school district.

In these studies, the production frontier is deterministic in that it is common to all firms, and any deviation from that frontier is attributable to differences in efficiency. The concept of a deterministic frontier ignores the possibility that a firm's performance may be affected by factors both within and outside its control. That is, combining the effects of any measurement error with other sources of stochastic variation in the dependent variable (e.g., an outlier) in the single one-sided error term may lead to biased estimation of technical inefficiency. In response to this, the concept of a stochastic production frontier was developed and extended by Aigner, Lovell, and Schmidt (1977), Meeusen and van den Broeck (1977), Battese and Corra (1977), Battese and Coelli (1988), Lee and Tyler (1978), Pitt and Lee (1981), Jondrow et al. (1982), Kalirajan and Flinn (1983), Bagi and Huang (1983), Schmidt and Sickles (1984), and Waldman (1984). The basic idea behind the stochastic frontier model as stated by Forsund, Lovell, and Schmidt (1980) is that the error term is composed of two parts: (1) the systematic component (i.e., traditional random error, v) that captures the effect of measurement error, other statistical noise, and the random shocks, and (2) the one-sided component that captures the effects of inefficiency.

Frontier production models have been analyzed either in the framework of the production function or by using duality in the form of a cost-minimizing or profit-maximizing framework. 
Barrow's (1991) study of schools in England tested various forms of the cost frontier and found the level of efficiency to be sensitive to the method of estimation. In their study of technical inefficiency in elementary schools in New York, Wyckoff and Lavinge (1991) estimate the production function directly and find that the index of technical inefficiency depends on the definition of educational output. For example, if output is measured by the level of cognitive skill of students rather than their college entrance test scores (i.e., the ACT, SAT, or any other type of composite test score consisting of reading, writing, and mathematics skills), the index of technical inefficiency based on each output measure will be different. Grosskopf et al. (1991) used a stochastic frontier and distance function to measure technical and allocative efficiency in Texas school districts and concluded that they were technically efficient but allocatively inefficient.

\section{Defining the Educational Production Function}

In the production of education, school districts use various school and nonschool inputs to produce multiple outputs, generally measured by achievement test scores. Since, the purpose of education is to develop the student's basic cognitive skills, these skills are often measured by the scores in reading, writing, and mathematics tests. However, there are references in the literature where output is measured either by the number of students graduating per year, student success in gaining admission into the higher education, or a student's future earning potential.

In most studies of the education production function, the measure of output is limited by the availability of data. School inputs that are associated with student achievement scores are typically measured by the student/teacher ratio, teacher educational qualifications and teaching experience, and various instructional and noninstructional expenditures per student. Nonschool inputs include 
socioeconomic status of the students (SES) and other environmental factors that influence student productivity. While family income, number of parents in the home, parental education, and ethnic background measure the SES of the students, geographic location (i.e., rural/urban) and net assessed value per student capture the environmental factors.

School inputs that are basically associated with the instructional and noninstructional activities are under the control of the school management. Most studies in educational production find an insignificant relationship between most of the school inputs and outputs. For example, see Walberg and Fowler (1987), Hanushek (1971), Deller and Rudnicki (1993), and Cooper and Cohn (1997). These studies and those by Hanushek (1986) and Grosskopf and Weber (1989) find a significant influence of SES and environmental factors on achievement scores.

A school district is technically efficient if it is observed to produce the maximum level of output from a given bundle of resources used or, conversely, uses minimum resources to produce a given level of output. In this study, the single output of our educational production function is measured by the average score on the 11th grade standardized battery test.

\section{Stochastic Specification of Technical Efficiency}

In the stochastic frontier model, a nonnegative error term representing technical inefficiency is subtracted from the traditional random error in the classical linear model. The general formulation of the model is:

$$
y_{i}=\beta_{1}+\beta_{2} x_{i 3}+\ldots+\beta_{k} x_{i k}+\varepsilon_{i}
$$

where $y_{i}$ is output and the $x_{i j}$ are inputs. It is postulated that $\varepsilon_{i}=v_{i}-u_{i}$ where $v_{i} \sim \mathrm{N}\left(0, \sigma_{v}^{2}\right)$

and $u_{i} \sim\left|\mathrm{N}\left(0, \sigma_{u}^{2}\right)\right|$, i.e., $u_{i} \geq 0$, and the $u_{i}$ and $v_{i}$ are assumed to be independent. The error term 
$\left(\varepsilon_{i}\right)$ is the difference between the standard white noise disturbance $\left(v_{i}\right)$ and the one-sided component $\left(u_{i}\right)$. The term $v_{i}$ allows for randomness across firms and captures the effect of measurement error, other statistical noise, and random shocks outside the firm's control. The one-sided component, $u_{i}$ captures the effect of inefficiency (Forsund, Lovell, and Schmidt 1980). Most of the earlier stochastic production frontier studies only calculated mean technical inefficiency of firms in the industry because they could not decompose the residual for individual observations into the two components. Jondrow et al. (1982) solve the problem by defining the functional form of the distribution of the one-sided inefficiency component and derive the conditional distribution of $\left[u_{i} \mid v_{i}-u_{i}\right]$ for two popular distribution cases (i.e., the half normal and the exponential) to estimate firm-specific technical inefficiency.

For this study, let the production function for the $i$ th school district be represented by:

$$
y_{i}=A \prod_{j=1}^{k} x_{j}^{\alpha}\left\ulcorner e^{v}\right.
$$

where $y$ is output and $x_{j}$ are exogenous inputs. A is the efficiency parameter and $v$ is the stochastic disturbance term. The production function in (2) is related to the stochastic frontier model by Aigner, Lovell, and Schmidt (1977), who specify A as:

$$
A=a_{O} e^{-u} u \geq 0
$$

where $a_{O}$ is a parameter common to all districts and $u$ is the degree of technical inefficiency that varies across school districts. Units for which $u=0$ are most efficient. A district is said to be technically inefficient if output is less than the maximum possible rate defined by the frontier. The term $v$ is the usual two-sided error term that represents shifts in the frontier due to favorable and unfavorable external factors and measurement error. 
After including the component of inefficiency (i.e., $e^{-u}$ ), the actual production function is written as:

$$
y_{i}=a_{O} \prod_{j=1}^{k} x_{i j}^{a_{\digamma}} e^{(v-u)} .
$$

If there is no inefficiency and potential output is denoted by $Y$, then the production function is written as:

$$
Y_{i}=a_{O} \prod_{j=l}^{k} x_{j}^{\alpha_{\digamma}} e^{v}
$$

Hence, the appropriate measure of technical efficiency is:

$$
\frac{\text { actual output }}{\text { potential output }}=\frac{y_{i}}{Y_{i}}=\frac{a_{O} e^{-u} \prod_{j=1}^{k} x_{j}^{a_{\digamma}} e^{v}}{a_{O} \prod_{j=1}^{k} x_{j}^{a_{\digamma}} e^{v}}=e^{-u}
$$

Potential output is the maximum possible when $u=0$ in equation (3). A technically efficient school district produces outputs (i. e., standardized test scores) that are on the stochastic production frontier, which is subject to random fluctuations captured by $v$. However, because of differences in managerial efficiency, actual performance deviates from the frontier.

Since, $u \geq 0,0 \leq e^{-u} \leq 1$, and $e^{-u}$ is a measure of technical efficiency, the mean technical efficiency is $E\left(e^{-u}\right)$. Thus, technical inefficiency is measured by $1-e^{-u}$, where $e^{-u}$ is technical efficiency bounded by 0 and 1 . That is, technical efficiency lies between 1 and 0 , and technical inefficiency is bounded between 0 and 1 . This study uses the method of estimation suggested by Jondrow et al. (1982) to estimate technical inefficiency in each school district. 


\section{DEA Specification of Technical Efficiency}

The nonparametric mathematical programming approach to frontier estimation is known as data envelopment analysis (DEA). This approach constructs the best practice production frontier as a piecewise linear envelopment of the available data on all producers in such a manner that all observed points lie on or below the frontier. In DEA, the performance of a producer is evaluated in terms of his ability to either shrink an input vector or expand an output vector subject to the restrictions imposed by the best observed practice. This measure of performance is relative in the sense, that efficiency in each school district is evaluated against the most efficient district and is measured by the ratio of maximal potential output to actual observed output. A simple input-oriented DEA model is presented in this section, and for a detailed methodological discussion see Seiford and Thrall (1990), Lovell (1993), Fare, Grosskopf, and Lovell (1994), and Chakraborty and Mohapatra (1997).

Following Fare et al. (1994), assume there are $K$ school districts using $N$ inputs, $x=\left(x_{1}, \ldots, x_{N}\right) \in \Re_{+}^{N}$, producing $M$ outputs denoted by $y=\left(y_{1}, \ldots, y_{M}\right) \in \Re_{+}^{M}$. We denote $N$ as $(K, N)$ matrix of inputs vector and $M$ as $(K, M)$ matrix of output vector of $K$ different school districts and $\left(x^{k}, y^{k}\right)$ represent the input/output vector or the activity of the $k$ th district. Assuming input and output are nonnegative, the piecewise linear input set satisfying the properties of constant returns to scale and strong disposability of inputs $(C, S)$ denotes all input vectors capable of producing at least output vector $y$,

$$
L(y \mid C, S)=\left\{x: y \leq z M, z N \leq x, z \in \Re_{+}^{K}\right\}, z \in \Re_{+}^{M}
$$

where $z$ is the $(1, K)$ intensity vector identifying to what extent a particular activity $\left(x^{k}, y^{k}\right)$ is utilized. The assumption of strong disposability as a feature of technology implies inputs can be increased 
without decreasing output, which excludes upward-sloping isoquants and noneconomic regions. Given the $(C, S)$ technology in the above specification, an input measure of technical efficiency for activity $k$ is the solution to the linear programming problem:

$$
F_{i}\left(y^{k}, x^{k} \mid C, S\right)=\operatorname{Min} \theta
$$

S.t.

$$
\begin{gathered}
y^{k} \leq z M \\
z M \leq \theta x^{k} \\
z \in \Re_{+}^{K}
\end{gathered}
$$

or

\section{$\operatorname{Min} \theta$}

$\theta z$

S.t.

$$
\begin{gathered}
y_{k m} \leq \sum_{k=l}^{K} z_{k} y_{k m}, \quad m=1,2, \ldots, M, \\
\sum_{k=l}^{K} z_{k} x_{k n} \leq \theta x_{k m}, \quad n=1,2, \ldots, N, \\
z_{k} \geq 0, \quad k=1,2, \ldots, K,
\end{gathered}
$$

Hence, $F_{i}\left(y^{k}, x^{k} \mid C, S\right)=1$ implies district $k$ is the most efficient and lies on the frontier, and any value less than 1 implies the district is operating above the frontier. The implication of the technical efficiency score using input-oriented DEA is the extent that the input vector may be reduced to produce the same output vector. The restrictive assumption of constant returns to scale on the production technology is further relaxed in nonincreasing $(N, S)$ and variable returns to scale $(V, S)$, imposing the following restrictions on the intensity vector as $\sum_{k=1}^{K} z_{k} \leq 1$ and $\sum_{k=1}^{K} z_{k}=1$, respectively. An input-oriented DEA measure of technical efficiency seeks equiproportionate shrinkage of input vectors while remaining on the same production frontier. Hence, this method assumes all 
inputs are capable of shrinkage. For the educational production function, inputs measuring SES of the students and environmental factors are fixed and unshrinkable. Hence, technical efficiency estimates from DEA, using these inputs along with other shrinkable inputs, will lead to specification error. One solution to this problem is to use a subvector efficiency model that specifically treats the SES as fixed and unshrinkable and the other is to use a conventional two-stage DEA model. Following McCatry and Yaisawarng (1993), we use a two-stage DEA model where efficiency scores from DEA using school inputs are regressed on the nonschool inputs (SES and environmental factors) using a Tobit model. The residuals of the Tobit model separate the effects of these fixed factors and measures pure technical efficiency that is bounded between $-\infty$ and 1 . Hence, the higher the value of the residual, the better is the performance of the school district.

\section{The Data Set}

Relevant data for the 40 school districts in Utah were collected from reports prepared by the Utah State Office of Education (1993) and the Utah Education Association (1993). The single output of our educational production function $(y)$ is measured by the battery test score at the 11th grade, which is a composite of reading, writing of language/English, and mathematics skills. The average district level data are aggregated over schools and over students. The school inputs used in this study are: the student/teacher ratio $\left(x_{1}\right)$, percentage of teachers with an advanced degree $\left(x_{2}\right)$, and percentage of teachers with over 15 years of experience $\left(x_{3}\right)$. Nonschool inputs consist of a percentage of students who qualify for Aid to Families with Dependent Children (AFDC) subsidized

lunch $\left(x_{4}\right)$, percentage of district population having completed high school $\left(x_{5}\right)$, and net assessed value per student $\left(x_{6}\right)$. While $x_{1}$ is a proxy for the level of instructional input, $x_{2}$ and $x_{3}$ measure 
quality of teaching inputs, and $x_{4}, x_{5}$, and $x_{6}$ measure the SES and the environmental factors. In the single equation model, the first three inputs $\left(x_{1}, x_{2}, x_{3}\right)$ are subject to control by management, whereas inputs $x_{4}$ through $x_{6}$ are beyond such control. The summary statistics for both inputs and output are reported in Table 1.

Measuring technical efficiency using DEA requires that some of these inputs be rescaled so that they are positively correlated with the output vector. For example, the student/teacher ratio $\left(x_{1}\right)$, and percentage of students receiving AFDC subsidized lunch input $\left(x_{4}\right)$ are negatively associated

Table 1. Summary Statistics for Utah School Districts, 1992-93a

\begin{tabular}{|c|c|c|c|c|}
\hline Variable & Mean & $\begin{array}{l}\text { Standard } \\
\text { Deviation }\end{array}$ & Minimum & Maximum \\
\hline Average $11^{\text {th }}$ grade test score & 52.100 & 7.523 & 30.000 & 68.000 \\
\hline Student/teacher ratio & 20.165 & 3.285 & 10.590 & 30.030 \\
\hline $\begin{array}{l}\text { Percentage of teachers with } \\
\text { advanced degree }\end{array}$ & 26.043 & 10.019 & 2.780 & 43.590 \\
\hline $\begin{array}{l}\text { Percentage of teachers with } \\
\text { over } 15 \text { years experience }\end{array}$ & 17.361 & 4.016 & 5.880 & 25.81 \\
\hline $\begin{array}{l}\text { Percentage of population with } \\
\text { high school diploma }\end{array}$ & 82.818 & 6.137 & 59.700 & 91.600 \\
\hline $\begin{array}{l}\text { Percentage of students } \\
\text { receiving subsidized lunch }\end{array}$ & 25.650 & 10.618 & 5.000 & 51.000 \\
\hline $\begin{array}{l}\text { Net assessed value per } \\
\text { student }\end{array}$ & 191,290 & 162,970 & 56,700 & 702,800 \\
\hline
\end{tabular}

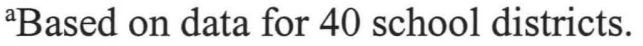


with the output measure in our stochastic model and are rescaled as teachers per student $\left(1 / x_{1}\right)$ and percentage of students buying their own lunch $\left(100-x_{4}\right)$ when using them as inputs in DEA.

Following Schmidt and Lovell (1979) and Battese and Coelli (1988), a Cobb-Douglas functional form of the production function is postulated. The educational production function in $\log$ linear form is:

$$
\ln y_{i}=\alpha_{O}+\beta_{1} \ln x_{1}+\beta_{2} \ln x_{2}+\beta_{3} \ln x_{3}+\beta_{4} \ln x_{4}+\beta_{5} \ln x_{5}+\beta_{6} \ln x_{6}+v-u
$$

where $y_{i}$ is the educational output (i.e., average test score), the $x_{i}$ 's are the inputs described above, and $v_{i} \sim \mathrm{N}\left(0, \sigma_{v}^{2}\right)$ and $u_{i} \sim\left|\mathrm{N}\left(0, \sigma_{u}^{2}\right)\right|$. The condition that $u_{i} \geq 0$ allows production to occur below the stochastic production frontier.

The following relationships between output and each explanatory variable are hypothesized:

$\underline{\text { Variable }}$

Student/teacher ratio

Percentage of teachers

with advanced degree

Percentage of teachers with

over 15 years of experience

Percentage of students receiving subsidized lunch

Percentage of population with high school education

Net assessed value per student $\underline{\text { Coefficient }}$

$\beta_{1}$

$\beta_{2}$

$\beta_{3}$

$\beta_{4}$

$\beta_{5}$

$\beta 6$
$<0$

Hypothesized Sign

$<0$

$>0$

$>0$

$>0$

$>0$ 


\section{Empirical Results}

Maximum-likelihood estimates ${ }^{5}$ of the parameters based on half normal and exponential distributions of $u$ are reported in Table 2. Except for the net assessed value per student, all the coefficients have correct sign but only the coefficient of the percentage of population with high school education is significant at the 0.05 level. The possible reason for a negative sign on net assessed value per student input is the presence of strong multicollinearity with other socioeconomic inputs. The coefficient on the education level of the district population implies that a $1 \%$ change in population with a high school diploma is associated with a $0.91 \%$ to $0.96 \%$ change in test scores. This indicates the importance of the environment for learning provided in the home. The negative sign on the student/teacher ratio is as expected and confirms the conventional wisdom that smaller classes are more conducive to better learning. Positive coefficients on teaching experience and teacher educational qualifications imply positive contributions of these inputs in the student learning process. Finally, the welfare variable has the expected negative sign, but the coefficient is not statistically significant.

These results are consistent with those obtained by Walberg and Fowler (1987) and Cooper and Cohn (1997), who found a positive effect of quality of instructional staff and weak negative effects of student/teacher ratio on achievement test scores. The coefficient of the parameter $\lambda$, which is equal to $\sigma_{u} / \sigma_{v}$, indicates the presence of inefficiency in the production process. A highly significant coefficient on $\lambda$ implies a higher value of $\sigma_{u}$ than $\sigma_{v}$, which implies a high degree of

\footnotetext{
LIMDEP.

${ }^{5}$ Parameters of stochastic frontier production function and the technical efficiency estimates are made using
} 
Table 2. Stochastic Frontier Parameter Estimates Dependent variable: Ln(test score)

\begin{tabular}{lcc}
\hline \hline Variable & MLE (Half Normal) & MLE (Exponential) \\
\hline Constant & 0.877 & 0.766 \\
& $(0.402)$ & $(0.463)$ \\
Ln(student/teacher ratio) & -0.289 & -0.196 \\
& $(-1.546)$ & $(-1.380)$ \\
Ln(percentage of teachers with & 0.024 & 0.057 \\
advanced degree) & $(0.382)$ & $(1.195)$ \\
Ln(percentage of teachers with & 0.032 & -0.016 \\
$\quad$ experience over 15 years) & $(0.234)$ & $(-0.206)$ \\
Ln(percentage of students receiving & -0.039 & -0.041 \\
subsidized lunch) & $(-0.430)$ & $(-0.739)$ \\
Ln(percentage of population with & $0.959^{*}$ & $0.909^{*}$ \\
high school diploma) & $(2.215)$ & $(3.029)$ \\
Ln(net assessed value per student) & -0.015 & -0.011 \\
& $(-0.329)$ & $(-0.308)$ \\
$\lambda$ & 12.705 & \\
$\theta^{\circledR}$ & $(0.468)$ & $(3.247)$ \\
Log of the Likelihood Function & 32.969 & 32.622 \\
\hline
\end{tabular}

t-statistics are in parentheses.

*Indicates coefficients are significant at $5 \%$ or lower probability.

${ }^{\circledR} \theta$ is defined as $z+\frac{\sigma_{v} \phi\left(z / \sigma_{v}\right)}{\Phi\left(z / \sigma_{v}\right)}$, where $z=\varepsilon-\theta \sigma_{v}^{2}$. 
inefficiency. The insignificant coefficient on $\lambda$ in Table 2 means that, on average, school districts in Utah are utilizing their resources efficiently.

The technical efficiency $\left(e^{-u}\right)$ estimates based on half normal and exponential distributions of the one-sided component of the disturbance are compared and contrasted in Table 3. While there are differences in the measures of technical efficiency between the half normal and exponential distributions, the rankings are very similar; the correlation coefficient for the two rankings is 0.964 . The mean efficiency is 0.8607 for the half normal estimates and 0.8852 for the exponential function. The size of the district (i.e., number of students) also is shown in column 3 of Table 3. There is no obvious relationship between size and efficiency discernible from these data.

In the case of half normal distributions, the most and the least efficient school districts have technical efficiency scores of 0.9698 and 0.5252 , respectively. While, analyzing the sources of inefficiency in the case of the latter, it is revealed that a high student/teacher ratio is mainly responsible for the poor performance that amounts to managerial inefficiency. Depending on the measure used, 18 to 24 of the school districts have efficiency measures of 0.90 or more. This probably should be construed as being good performance, given the nature of the production system and the constraints within which resource allocation decisions can be made, especially with regard to personnel, many of whom have rather strong employment security.

Table 4 presents the results obtained from the two-stage DEA model. While technical efficiency estimates, assuming constant $(C, S)$ and nonincreasing $(N, S)$ returns to scale and strong disposability of inputs (not reported in this study), produced almost the same efficiency scores, the variable returns to scale $(V, S)$ assumption produced higher efficiency scores for each district. 
Table 3. Measuring Technical Efficiency Using Half Normal and Exponential Distributions

\begin{tabular}{|c|c|c|c|c|c|c|}
\hline \multirow{2}{*}{$\begin{array}{l}\text { District } \\
\text { Code }\end{array}$} & \multirow[b]{2}{*}{ District } & \multirow[b]{2}{*}{ District Size } & \multicolumn{2}{|c|}{ Half-Normal } & \multicolumn{2}{|c|}{ Exponential } \\
\hline & & & Efficiency & Rank & Efficiency & Rank \\
\hline 1 & Alpine & 1,576 & 0.9489 & 8 & 0.9644 & 6 \\
\hline 2 & Beaver & 385 & 0.8521 & 25 & 0.8880 & 27 \\
\hline 3 & Box Elder & 6,795 & 0.9033 & 9 & 0.9357 & 15 \\
\hline 4 & Cache & 2,540 & 0.9224 & 19 & 0.9478 & 20 \\
\hline 5 & Carbon & 13,565 & 0.8194 & 21 & 0.8528 & 17 \\
\hline 6 & Daggett & 40,322 & 0.9419 & 14 & 0.9523 & 10 \\
\hline 7 & Davis & 3,137 & 0.9148 & 20 & 0.9444 & 23 \\
\hline 8 & Duchesne & 191 & 0.7958 & 23 & 0.8263 & 25 \\
\hline 9 & Emery & 7,355 & 0.8569 & 28 & 0.8915 & 28 \\
\hline 10 & Garfield & 12,593 & 0.7628 & 35 & 0.7885 & 34 \\
\hline 11 & Grand* & 14,596 & 0.9698 & 1 & 0.9745 & 1 \\
\hline 12 & Granite & 5,475 & 0.8756 & 18 & 0.9108 & 21 \\
\hline 13 & Iron & 5,150 & 0.9416 & 13 & 0.9587 & 13 \\
\hline 14 & Jordan & 11,190 & 0.8806 & 16 & 0.9175 & 16 \\
\hline 15 & Juab & 25,538 & 0.7540 & 33 & 0.7870 & 33 \\
\hline 16 & Kane & 57,116 & 0.9547 & 17 & 0.9667 & 9 \\
\hline 17 & Millard & 79,573 & 0.7606 & 36 & 0.7902 & 36 \\
\hline 18 & Morgan & 68,843 & 0.8774 & 24 & 0.9156 & 26 \\
\hline 19 & Nebo & 6,799 & 0.8491 & 26 & 0.8877 & 29 \\
\hline 20 & No. Sanpete* & 5,894 & 0.6603 & 40 & 0.6821 & 40 \\
\hline 21 & No. Summit & 1,415 & 0.7590 & 37 & 0.7882 & 37 \\
\hline 22 & Park City & 4,411 & 0.9576 & 5 & 0.9677 & 8 \\
\hline 23 & Piute & 580 & 0.9713 & 4 & 0.9745 & 3 \\
\hline 24 & Rich & 1,889 & 0.8763 & 29 & 0.9128 & 24 \\
\hline 25 & San Juan & 2,899 & 0.5252 & 39 & 0.5288 & 39 \\
\hline 26 & Sevier & 26,832 & 0.8289 & 31 & 0.8633 & 32 \\
\hline 27 & So. Sanpete & 3,400 & 0.9058 & 22 & 0.9378 & 18 \\
\hline 28 & So. Summit & 549 & 0.7151 & 38 & 0.7379 & 38 \\
\hline 29 & Tintic & 1,395 & 0.8060 & 32 & 0.8232 & 30 \\
\hline 30 & Tooele & 17,161 & 0.8668 & 11 & 0.9016 & 14 \\
\hline 31 & Uintah & 4,859 & 0.9009 & 7 & 0.9327 & 4 \\
\hline 32 & Wasatch & 1,644 & 0.9485 & 3 & 0.9638 & 2 \\
\hline 33 & Washington & 1,097 & 0.9545 & 2 & 0.9669 & 7 \\
\hline 34 & Wayne & 241 & 0.9248 & 30 & 0.9520 & 22 \\
\hline 35 & Weber & 12,589 & 0.7711 & 27 & 0.8011 & 31 \\
\hline 36 & Salt Lake & 3,861 & 0.9139 & 12 & 0.9378 & 12 \\
\hline 37 & Ogden & 944 & 0.7560 & 34 & 0.7804 & 35 \\
\hline 38 & Provo & 1,106 & 0.9824 & 6 & 0.9820 & 5 \\
\hline 39 & Logan & 3,400 & 0.9489 & 10 & 0.9628 & 11 \\
\hline \multirow[t]{2}{*}{40} & Murray & 2,352 & 0.8737 & 15 & 0.9092 & 19 \\
\hline & Mean & 11,531 & 0.8607 & & 0.8852 & \\
\hline
\end{tabular}

*Indicate the most and the least efficient school districts. 
Table 4. Technical Efficiency Using DEA and Conditional Ordering of Tobit Residuals

\begin{tabular}{|c|c|c|c|c|}
\hline S.L.\# & School District & T Efficiency VRS & School District & Tobit Model Residuals \\
\hline 1 & Alpine* & 1.0000 & Piute & 0.1013 \\
\hline 2 & Wasatch & 1.0000 & Daggett & 0.1011 \\
\hline 3 & Park City* & 1.0000 & Juab & 0.0867 \\
\hline 4 & Juab & 1.0000 & Wayne & 0.0846 \\
\hline 5 & Piute & 1.0000 & Grand & 0.0801 \\
\hline 6 & Grand & 1.0000 & Rich & 0.0623 \\
\hline 7 & Washington & 1.0000 & Washington & 0.0557 \\
\hline 8 & Wayne & 1.0000 & Wasatch & 0.0537 \\
\hline 9 & Daggett & 1.0000 & Box Elder. & 0.0514 \\
\hline 10 & Box Elder & 1.0000 & Ogden & 0.0500 \\
\hline 11 & Davis* & 0.9818 & Alpine & 0.0405 \\
\hline 12 & Rich* & 0.9785 & Sevier & 0.0357 \\
\hline 13 & Morgan & 0.9775 & Park City & 0.0344 \\
\hline 14 & Logan & 0.9772 & Millard & 0.0343 \\
\hline 15 & Nebo & 0.9733 & Logan & 0.0249 \\
\hline 16 & Sevier & 0.9656 & Nebo & 0.0200 \\
\hline 17 & Ogden* & 0.9648 & Uintah & 0.0189 \\
\hline 18 & Murray & 0.9592 & Davis & 0.0158 \\
\hline 19 & Millard* & 0.9498 & Kane & 0.0152 \\
\hline 20 & Cache* & 0.9459 & So. Sanpete & 0.0147 \\
\hline 21 & Kane & 0.9446 & Carbon & 0.0127 \\
\hline 22 & Granite & 0.9439 & Tooele & 0.0121 \\
\hline 23 & Beaver & 0.9433 & Morgan & 0.0101 \\
\hline 24 & So. Sanpete & 0.9398 & Murray & 0.0072 \\
\hline 25 & Tooele & 0.9386 & Beaver & 0.0069 \\
\hline 26 & Weber & 0.9375 & Granite & -0.0040 \\
\hline 27 & Provo & 0.9373 & Provo & -0.0074 \\
\hline 28 & Iron & 0.9206 & Weber & -0.0129 \\
\hline 29 & Carbon & 0.9198 & Cache & -0.0174 \\
\hline 30 & Uintah* & 0.9166 & Iron & -0.0212 \\
\hline 31 & Jordan & 0.9003 & Duchesne & -0.0340 \\
\hline 32 & No. Summit & 0.8963 & No. Sanpete & -0.0375 \\
\hline 33 & No. Sanpete & 0.8827 & Garfield & -0.0375 \\
\hline 34 & Garfield & 0.8825 & Jordan & -0.0571 \\
\hline 35 & Duchesne & 0.8749 & No. Summit & -0.0708 \\
\hline 36 & So. Summit & 0.8721 & Salt Lake & -0.0730 \\
\hline 37 & Salt Lake & 0.8487 & So. Summit & -0.0801 \\
\hline 38 & Emery & 0.8287 & Emery & -0.0999 \\
\hline 39 & San Juan & 0.7026 & San Juan & -0.1184 \\
\hline 40 & Tintic & 0.6484 & Tintic & -0.2506 \\
\hline
\end{tabular}

*Indicates school districts with large socioeconomic influences. 
Technical efficiency estimates, using the variable returns to scale assumption with strong disposability of inputs $(V, S)$, are presented in column 3 and the Tobit residuals are presented in column 5 of Table 4 . It is observed that the ordering of the school districts in column 2 , based on technical efficiency scores from DEA, and the ordering in column 4, based on the Tobit residuals, did not change significantly before and after the SES of the students were considered. For example, highly inefficient school districts, such as Provo, Salt Lake City, Emery, San Juan, and Tintic, remain inefficient in both columns 2 and 4 . This indicates that the poor performance of these units is due not to the low SES of students but rather to managerial inefficiency. However, when the effects of SES and environmental factors were eliminated in the Tobit residuals, which measure pure technical efficiency, the ordering of Alpine, Davis, Park City, and Cache districts dropped from 1, 3, 11, and 20 in column 2 to 11, 13, 18, and 29 in column 4, respectively. This implies that the higher technical efficiency of these school districts at the first stage of DEA (i.e., column 2) are not due to managerial efficiency but because most students come from a higher SES background. Conversely, efficiency increased in the Rich, Ogden, Millard, and Uintah districts increased when the effects of the SES and environmental factors were eliminated in the Tobit residuals, suggesting that most of these students come from a lower SES background.

In Table 5, the relative performance of the districts based on the stochastic frontier methodology (half normal) are compared with the two-stage DEA model. Recall that the technical efficiency estimates and their rankings obtained from the stochastic method and the first-stage DEA 
Table 5. Stochastic and Nonstochastic Technical Efficiency Comparison

\begin{tabular}{|c|c|c|c|c|}
\hline S.L. \# & District & $\begin{array}{l}\text { Half-Normal } \\
\text { Efficiency }\end{array}$ & District & Tobit Model Residuals \\
\hline 1 & Provo* & 0.9824 & Piute & 0.1013 \\
\hline 2 & Piute & 0.9713 & Daggett & 0.1011 \\
\hline 3 & Grand & 0.9698 & Juab & 0.0867 \\
\hline 4 & Park City* & 0.9576 & Wayne & 0.0846 \\
\hline 5 & Kane* & 0.9547 & Grand & 0.0801 \\
\hline 6 & Washington & 0.9545 & Rich & 0.0623 \\
\hline 7 & Logan* & 0.9489 & Washington & 0.0557 \\
\hline 8 & Alpine & 0.9489 & Wasatch & 0.0537 \\
\hline 9 & Wasatch & 0.9485 & Box Elder. & 0.0514 \\
\hline 10 & Daggett & 0.9419 & Ogden & 0.0500 \\
\hline 11 & Iron & 0.9416 & Alpine & 0.0405 \\
\hline 12 & Wayne & 0.9248 & Sevier & 0.0357 \\
\hline 13 & Cache & 0.9224 & Park City & 0.0344 \\
\hline 14 & Davis & 0.9148 & Millard & 0.0343 \\
\hline 15 & Salt Lake* & 0.9139 & Logan & 0.0249 \\
\hline 16 & So. Sanpete & 0.9058 & Nebo & 0.0200 \\
\hline 17 & Box Elder & 0.9033 & Uintah & 0.0189 \\
\hline 18 & Uintah & 0.9009 & Davis & 0.0158 \\
\hline 19 & Jordan & 0.8806 & Kane & 0.0152 \\
\hline 20 & Morgan & 0.8774 & So. Sanpete & 0.0147 \\
\hline 21 & Rich** & 0.8763 & Carbon & 0.0127 \\
\hline 22 & Granite & 0.8756 & Tooele & 0.0121 \\
\hline 23 & Murray & 0.8737 & Morgan & 0.0101 \\
\hline 24 & Tooele & 0.8668 & Murray & 0.0072 \\
\hline 25 & Emery & 0.8569 & Beaver & 0.0069 \\
\hline 26 & Beaver & 0.8521 & Granite & -0.0040 \\
\hline 27 & Nebo & 0.8491 & Provo & -0.0074 \\
\hline 28 & Sevier & 0.8289 & Weber & -0.0129 \\
\hline 29 & Carbon & 0.8194 & Cache & -0.0174 \\
\hline 30 & Tintic* & 0.8060 & Iron & -0.0212 \\
\hline 31 & Duchesne* & 0.7958 & Duchesne & -0.0340 \\
\hline 32 & Weber & 0.7711 & No. Sanpete & -0.0375 \\
\hline 33 & Garfield & 0.7628 & Garfield & -0.0375 \\
\hline 34 & Millard** & 0.7606 & Jordan & -0.0571 \\
\hline 35 & No. Sanpete & 0.7590 & No. Summit & -0.0708 \\
\hline 36 & Ogden $* *$ & 0.7560 & Salt Lake & -0.0730 \\
\hline 37 & Juab** & 0.7540 & So. Summit & -0.0801 \\
\hline 38 & So. Summit & 0.7151 & Emery & -0.0999 \\
\hline 39 & No. Sanpete & 0.6603 & San Juan & -0.1184 \\
\hline 40 & San Juan & 0.5252 & Tintic & -0.2506 \\
\hline
\end{tabular}

*Indicates higher performance in stochastic estimation.

${ }^{* *}$ Indicates higher performance in two-stage DEA. 
cannot be compared directly because two different sets of input vectors are used in these two estimation methods. While the stochastic method uses both school and nonschool inputs, only school inputs are considered in the first stage DEA. From Table 5, it is observable that the districts that are highly technically efficient in stochastic estimation (e.g., Provo, Park City, Kane, Logan, Salt Lake City, Tintic, and Duchesne (column 2)) are less efficient when compared using the Tobit residuals (column 4). The reason is due to the basic assumption about the random disturbance term. In the stochastic specification, a deviation of the production function from the frontier is the sum of a random component $\left(v_{i}\right)$ and the inefficiency component $\left(u_{i}\right)$. Nonstochastic DEA specification does not allow for such randomness where any deviation of the production function from the maximal is regarded as inefficiency. School districts that appear highly efficient under stochastic specification contain a relatively large random component of the error term $\left(v_{i}\right)$ when compared to the inefficiency component $\left(u_{i}\right)$. Hence, in two-stage DEA, Tobit residuals for these school districts reflect less efficiency. However, districts that are found to be inefficient in the stochastic estimation and contain a relatively small random component of the error term $\left(v_{i}\right)$ show better performance in the two-stage DEA. Examples of such school districts are Rich, Millard, Ogden, and Juab.

\section{Summary}

This study measures technical efficiency in each of the 40 school districts in Utah using both stochastic and nonstochastic estimation methods. In stochastic estimation, substantial variation in technical efficiency among school districts is observed, and it is invariant as to the distributional assumption of the one-sided component of the error term $\varepsilon$. The results of this study suggest that most of the school districts in Utah are technically efficient with mean efficiency scores $86.07 \%$ and 
$88.52 \%$ for the half-normal and exponential distributions, respectively. The empirical results also indicate that the single most important factor explaining student performance is the level of parental education.

The two-stage DEA analysis of efficiency also indicates that socioeconomic and environmental factors have a strong influence on student success. There does not appear to be systematic similarity among the most and least efficient school districts. In terms of size, ten districts at each end of the efficiency scale include both large and small districts, and they are geographically dispersed. Also, there is no apparent correlation between efficiency and the nature of the local economic base. Both groups include districts in areas where agriculture, mineral extraction, or tourism is the predominant economic activity.

These have several important policy implications. For example, districts with high SES students might improve efficiency by better management of controllable inputs (i.e., teaching and other staff, student work load, etc.) and/or adoption of programs that link part of teacher compensation to student performance. Districts with large number of low SES students face a more difficult challenge as they train students who have less intellectual support at home. In such districts, efficiency might be enhanced by some resource allocation to: (1) pre-kindergarten programs to better prepare young children for entering school, (2) adult education, and/or (3) facilitate greater teacher/parent interaction designed to encourage parental support of the student's educational activity. 


\section{References}

Aigner, D. J., and S-F. Chu. 1968. “On Estimating Industry Production Functions.” American Economic Review 58:826-39.

Aigner, D. J., C. A. K. Lovell, and P. Schmidt. 1977. "Formulation and Estimation of Stochastic Frontier Production Function Models," Journal of Econometrics 6:21-37.

Ali, M., and D. Byerlee. 1991, "Economic Efficiency of Small Farmers in a Changing World: A Survey of Recent Evidence.” Journal of International Development 3:1-27.

Bagi, F. S., and C. J. Huang. 1983. "Estimating Production Technical Efficiency for Industrial Farms in Tennessee." Canadian Journal of Agricultural Economics 31:249-56.

Barrow, M. M. 1991. "Measuring Local Education Authority Performance: A Frontier Approach." Economics of Education Review 10:19-27.

Battese, G. E., and T. J. Coelli. 1988. "Prediction of Farm-Level Technical Efficiencies With a Generalized Frontier Production Function and Panel Data." Journal of Econometrics 38:387-99.

Battese, G. E., and G. S. Corra. 1977. "Estimation of the Production Frontier Model: With Application to the Pastoral Zone of Eastern Australia." Australian Journal of Agricultural Economics 21:169-79.

Bessent, A., and W. Bessent. 1980. "Determining the Comparative Efficiency of Schools Through Data Envelopment Analysis.” Educational Administration Quarterly 16:57-75.

Bessent, A., W. Bessent, J. Kennington, and B. Reagan. 1982. "An Application of Mathematical Programming to Assess Productivity in the Houston Independent School District." Management Science 28:1355-67.

Chakraborty, K., and S. Mohapatra. 1997. "Dynamic Productivity, Efficiency, and Technical Innovation in Education: A Methematical Programming Approach Using Data Envelopment Analysis.” Economic Research Institute Study Paper \#97-08, Utah State University, Logan, Utah.

Charnes, A., W. Cooper, and E. Rhodes. 1978. "Measuring the Efficiency of Decision Making Units." European Journal of Operational Research 2:429-44.

Coelli, T. J. 1995. "Recent Developments in Frontier Modelling and Efficiency Measurement." Australian Journal of Agricultural Economics 39:219-45. 
Cooper, S. T., and E. Cohn. 1997. "Estimation of a Frontier Production Function for South Carolina Educational Process." Economics of Education Review 16:209-25.

Debreu, G. 1951. “The Coefficient of Resource Utilization.” Econometrica 19:273-92.

Deller, S. C., and E. Rudnicki. 1993. "Production Efficiency in Elementary Education: The Case for Maine Public Schools.” Economics of Education Review 12(1):45-57.

Fare, R., S. Grosskopf, and C. A. K. Lovell. 1994. Production Frontiers. Cambridge, England: Cambridge University Press.

Farrell, M. J. 1957. "The Measurement of Productive Efficiency." Journal of Royal Statistical Society, Series A, General, 120(Part A):253-81.

Forsund, E. R., C. A. K. Lovell, and P. Schmidt. 1980. “A Survey of Frontier Production Functions and Their Relationship to Efficiency Measurement." Journal of Econometrics 13:5-25.

Greene, W. H. 1993. "The Econometric Approach to Efficiency Analysis.” In H. O. Fried, C.A. K. Lovell, and S. S. Schmidt (eds.), The Measurement of Production Efficiency: Techniques and Applications, New York: Oxford University Press.

Grosskopf, S., K., Hayes, L. Taylor, and W. Weber. 1991. "Teacher Salaries and Teacher Productivity." Paper presented at Western Economic Association Meetings, Seattle, Washington, July 5-9.

Grosskopf, S., and W. Weber. 1989. "Measuring School District Performance.” Public Finance Quarterly 17:409-29.

Hanushek, E. A. 1971. "Teacher Characteristics and Gains in Student Achievement: Estimation Using Micro Data." American Economic Review 61(2):280-8.

Hanushek, E. A. 1986 "The Economics of Schooling: Production and Efficiency in Public Schools." Journal of Economic Literature 24:1141-77.

Jondrow, J., C. A. K. Lovell, I. S. Materov, and P. Schmidt. 1982. “On the Estimation of Technical Inefficiency in the Stochastic Frontier Production Function Model." Journal of Econometrics 19:233-8.

Journal of Econometrics. 1990. "Frontier Analysis: Parametric and Nonparametric Approaches. Annals 1990-4, A Supplement." Amsterdam, North Holland.

Kalirajan, K. P., and J. C. Flinn. 1983. "The Measurement of Farm Specific Technical Efficiency." Pakistan Journal of Applied Economics 2:167-80. 
Klitgaard, R., and G. Hall. 1975. “Are There Unusually Effective Schools?” Journal of Human Resources 10:90-106.

Koopmans, T. C. 1951. Activity Analysis of Production and Allocation. New York: Wiley.

Lee, L. F., and W. G. Tyler. 1978 “A Stochastic Frontier Production Function and Average Efficiency: An Empirical Analysis.” Journal of Econometrics 7:385-90.

Levin, H. 1974. "Measuring Efficiency in Educational Production.” Public Finance Quarterly 2:3-24.

Levin, H. 1976. "Concepts of Economic Efficiency and Education Production.” In J. T. Froomkun, D.T. Jamison, and R. Renders (eds.), Education as an Industry, Cambridge, Massachusetts: Ballinger Publishing Co. for National Bureau of Economic Research.

Lovell, C. A. K. 1993. "Production Frontiers and Productive Efficiency." In H. O. Fried, C. A. K. Lovell, and S. S. Schmidt (eds.), The Measurement of Productive Efficiency: Techniques and Applications, Chapter 1, New York: Oxford University Press.

McCarty, T. A., and S. Yaisawarng. 1993. "Technical Efficiency in New Jersey Schools.” In H. O. Fried, C. A. K. Lovell, and S. S. Schmidt (eds.), The Measurement of Production Efficiency: Techniques and Applications, Chapter 10, New York: Oxford University Press.

Maddala, G. S. 1977. "Errors in Variables and Nonnormal Errors.” Chapter 13 in Econometrics, New York: McGraw-Hill Book Company.

Meeusen, W., and J. van den Broeck. 1977. "Efficiency Estimation from Cobb-Douglas Production Frontiers with Composed Error.” International Economic Review 18:435-44.

Pitt, M. M., and L. F. Lee. 1981. "Measurement and Sources of Technical Inefficiency in the Indonesian Weaving Industry." Journal of Development Economics 9:43-64.

Ray, S. C. 1991. "Resource-Use Efficiency in Public Schools: A Study of Connecticut Data." Management Science 37:1621-8.

Schmidt, P. S., and C. A. K. Lovell. 1979. "Estimating Technical and Allocative Inefficiency Relative to Stochastic Production and Cost Frontiers." Journal of Econometrics 9:343-66.

Schmidt, P. S., and R. C. Sickles. 1984. "Production Frontiers and Panel Data." Journal of Business and Economic Statistics 2:367-74.

Seiford, L. M., and R. M. Thrall. 1990. "Recent Development in DEA: The Mathematical Programming Approach to Frontier Analysis." Journal of Econometrics 46(1/2):7-38. 
U. S. Department of Commerce. 1994. Statistical Abstract of the United States, 1994. Washington, D.C.: Bureau of Census, Economic and Statistics Administration.

Utah Education Association. 1993. Teacher Salary Schedules. Research Bulletin, Vol. 38, No. 2, Salt Lake City, Utah, March.

Utah State Office of Education. 1993. Summary of Statistical and Financial Data of the Utah State Superintendent of Public Instruction, 1992-93. Salt Lake City, Utah, September.

Walberg, H., and W. Fowler. 1987. "Expenditure and Size Efficiencies of Public School Districts." Educational Researcher 16:5-13.

Waldman, D. M. 1984. "Properties of Technical Efficiency Estimators in the Stochastic Frontier Model." Journal of Econometrics 25:353-64.

Wyckoff, J. H., and J. Lavinge. 1991. "The Relative Inefficiency of Public Elementary Schools in New York." Working Paper, State University of New York, Albany. 


\section{Appendix}

Here, the technical inefficiency error term $u$ is assumed to be of the half-normal and exponential type. Results based on both of these distributional assumptions about $u$ are reported.

To estimate equation (3) by the maximum-likelihood method we need to know the probability density function ( $p d f)$ of $\varepsilon_{i}$, which is composed of $u_{i}$ and $v_{i}$. The $p d f$, mean, and variance of $u_{i}$ and $v_{i}$ are written as:

$$
\begin{gathered}
p d f \text { of } v_{i}=f\left(v_{i}\right)=\frac{1}{\sqrt{2 \pi \sigma_{v}}} e^{-\frac{v_{o}^{\prime}}{2 \sigma_{v}^{\prime \prime}}} \\
e\left(v_{I}\right)=0, \quad \text { and } \quad \operatorname{Var}(v)=\sigma^{2}, \\
p d f \text { of } u_{i}=f\left(u_{i}\right)=\frac{2}{\sqrt{2 \pi \sigma_{u}}} e^{-\frac{u_{o}^{\prime}}{2 \sigma_{\sigma}^{l 1}}}, \quad u_{i} \geq 0
\end{gathered}
$$

The half-normal distribution (A-2) has the following mean and variance (Maddala 1977; Aigner, Lovell, and Schmidt 1977):

$$
E\left(u_{i}\right)=\frac{\sqrt{2}}{\sqrt{\pi}} \sigma_{u} \quad \text { and } \quad \operatorname{Var}(u)=\frac{\pi-2}{\pi} \sigma_{u}^{2} .
$$

Assuming $u_{i}$ follows a one-parameter exponential distribution with $p d f$ written as:

$$
p d f \text { of } u_{i}=f\left(u_{i}\right)=f(u)=\frac{e^{\frac{-u}{\sigma_{o}}}}{\sigma_{u}}
$$

To formulate the log-likelihood function, the density function of the composite residual (v-u) (i.e., the joint density function of $f(v, u))$ is formulated and then transformed into a joint density of $\varepsilon$ and 
$u$ by integrating $u$ from 0 to $\propto$. Following Maddala (1977), the $p d f$ of $\varepsilon$, which is a composite of $v$ and $u$ is written as:

$$
f(\varepsilon)=\frac{\sqrt{2}}{\sigma \sqrt{\pi}}\left[1-F\left(\frac{\varepsilon \lambda}{\sigma}\right)\right] e^{\left(\frac{\varepsilon^{2}}{2 \sigma^{2}}\right)}
$$

where $\sigma^{2}=\sigma_{u}^{2}+\sigma_{v}^{2}, \lambda=\sigma_{u} / \sigma_{v}$, and $F\left(\frac{\varepsilon \lambda}{\sigma}\right)$ is the cumulative density function $(c d f)$ of the normal variable evaluated at $\frac{\varepsilon \lambda}{\sigma}$.

If we have a sample of $\mathrm{n}$ observations, we can form the relevant log-likelihood function as:

$$
\ln L\left(y \mid \beta_{1}, \ldots, \beta_{5}, \lambda, \sigma^{2}\right)=n \ln \frac{\sqrt{2}}{\sqrt{\pi}}+n \ln \frac{1}{\sigma}+\sum_{i=1}^{n} \ln \left[1-F\left(\frac{\varepsilon_{i} \lambda}{\sigma}\right)\right]-\frac{1}{2 \sigma^{2}} \sum_{i=1}^{n} \varepsilon_{i}^{2}
$$

It should be noted that the meaning of $1-F(\cdot)$, where $F$ is evaluated at $\frac{\varepsilon \lambda}{\sigma}=\frac{-\mu *}{\sigma *}$, is the probability that a $N\left(\mu *, \sigma *^{2}\right)$ variable with $\mu *=-\frac{\sigma_{u}^{2} \varepsilon}{\sigma^{2}}$ and $\sigma *^{2}=-\frac{\sigma_{u}^{2} \sigma_{v}^{2}}{\sigma^{2}}$ is positive. Differentiating equation (A-5) with respect to the unknown parameters and setting the partial derivatives equal to zero, we solve for an estimate of $\beta_{1}, \ldots, \beta_{5}, \lambda$, and $\sigma^{2}$.

Individual specific estimates of inefficiency measured by Jondrow et. al. (1982), using the conditional mean of $u$ given $\varepsilon$, involve the following steps:

First find the joint density of $u$ and $v$, which may be written as :

$$
f(u, v)=f(u) f(v)=\frac{1}{\pi \sigma_{u} \sigma_{v}} \exp \left[-\frac{1}{2 \sigma_{u}^{2}} u^{2}-\frac{1}{2 \sigma_{v}^{2}} v^{2}\right], \quad u \geq 0
$$

Then, using the relationship of $\varepsilon=v-u$, the joint density of $u$ and $\varepsilon$ is

$$
f(u, \varepsilon)=\frac{1}{\pi \sigma_{u} \sigma_{v}} \exp \left[-\frac{1}{2 \sigma_{u}^{2}} u^{2}-\frac{1}{2 \sigma_{v}^{2}}\left(u^{2}+\varepsilon^{2}+2 u \varepsilon\right)\right] .
$$


Therefore, following Jondrow et. al. (1982), the conditional density of $u$ given $\varepsilon$, for half normal distribution, is:

$$
f\left(u_{i} \mid \varepsilon_{i}\right)=\frac{f(u, \varepsilon)}{f(\varepsilon)}=\frac{1}{1-F \sqrt{2 \pi \sigma_{*}}} \exp \left[\frac{-1}{2 \sigma_{u}^{2}} u^{2}-\frac{1}{2 \sigma_{v}^{2}} v^{2}\right], \quad u \geq 0
$$

and the mean of this conditional density function is written as:

$$
E\left[u_{i} \mid \varepsilon_{i}\right]=\mu_{*}+\sigma_{*} \frac{f\left(\mu_{*} / \sigma_{*}\right)}{1-F\left(\mu_{*} / \sigma_{*}\right)}
$$

where $f(\cdot)$ and $F(\cdot)$ represent the standard normal density and cumulative distribution functions, respectively.

In the exponential case the technical inefficiency component of the error term, $u$, follows one-parameter distribution. The density function of $u$ is given in (A-3). As mentioned by Jondrow et al. (1982), the "results are similar to those for the half normal case."

Let $A=\frac{\varepsilon}{\sigma_{v}}+\frac{\sigma_{v}}{\sigma_{u}}$, then the mean of the conditional distribution of $u$ given $\varepsilon$ is written as:

$$
E(u / \varepsilon)=\sigma_{v}\left[\frac{f(A)}{1-F(A)}-A\right]
$$

